\title{
The Selective Dopamine D4 Receptor Antagonist, PNU-101387G, Prevents Stress-Induced Cognitive Deficits in Monkeys
}

Amy F.T. Arnsten, Ph.D., Beth Murphy, M.D., Ph.D., and Kalpana Merchant, Ph.D.

Stress exposure impairs the cognitive functioning of the prefrontal cortex (PFC). Previous research has examined the dopamine (DA) D1 receptor mechanisms underlying this response. The current study performed a preliminary examination of the role of $D 4$ receptor mechanisms by determining whether the selective $D 4$ receptor antagonist, PNU-101387G, could prevent stress-induced working memory deficits in monkeys. Animals were tested on the delayed response task following treatment with PNU-101387G (0 or $0.1-0.8 \mathrm{mg} / \mathrm{kg}, 60-\mathrm{min}$ pretreatment), and the pharmacological stressor, FG7142 (0 or $0.2 \mathrm{mg} / \mathrm{kg}$, 30-min pretreatment).
FG7142 significantly impaired delayed response performance relative to vehicle; PNU-101387G pretreatment produced a dose-related reversal of the FG7142 response. PNU-101387G had no significant effects on its own, but there were trends toward improvement at low doses and impairment at higher doses. Further studies in a larger number of animals appear warranted. These preliminary findings suggest that D4 receptor mechanisms contribute to stress-induced cognitive dysfunction. [Neuropsychopharmacology 23:405-410, 2000] (C) 2000 American College of Neuropsychopharmacology. Published by Elsevier Science Inc.
KEY WORDS: Memory; Prefrontal cortex; Stress; Dopamine; D4 receptors; FG7142K

Exposure to stress can exacerbate or precipitate neuropsychiatric disorders such as schizophrenia and affective disorders involving deficits in higher cognitive functions (Mazure 1995). Thus, it is important to understand the mechanisms by which stress exposure alters higher cortical function. For years it has been appreci-

From the Section of Neurobiology (AFTA) and Department of Pharmacology (BM), Yale University School of Medicine, New Haven, CT; Pharmacia and Upjohn, Inc. (KM), Kalamazoo, MI.

Address correspondence to: Dr. Amy F.T. Arnsten, Section of Neurobiology, Box 208001, Yale Medical School, New Haven, CT 06520-8001.

Received January 17, 2000; revised April 13, 2000; accepted April 20,2000 ated that even mild stress exposure releases monoamines in the prefrontal cortex (PFC; e.g., Goldstein et al. 1996; Kaneyuki et al. 1991; Thierry et al. 1976). The PFC is critical for guiding behavior using working memory (Goldman-Rakic 1987). Our lab has shown that stress impairs working memory performance in rats and monkeys via excessive stimulation of catecholamine receptors (reviewed in Arnsten and Goldman-Rakic 1998; Birnbaum et al. 1999). A continuing goal of this research is to identify the receptor subtypes underlying stressinduced PFC deficits.

The effects of stress have been examined using spatial working memory paradigms such as the delayed response task which are tightly linked to PFC function in monkeys (Goldman and Rosvold 1970). Exposure to either loud noise stress or to a pharmacological stressor (the inverse benzodiazepine agonist, FG7142) impaired delayed response performance in monkeys (Arnsten and Goldman-Rakic 1998; Murphy et al. 1996). In con- 
trast, these same stressors had no effect on discrimination tasks with similar motor and motivational needs that do not rely on PFC function (Arnsten and Goldman-Rakic 1998; Murphy et al. 1996). A similar pattern has been observed in humans, where loud noise stress impaired performance of tasks associated with the PFC such as the Stroop interference task (Hartley and Adams 1974), but facilitated simple or well-rehearsed tasks (reviewed in Broadbent 1971).

Much research to date has focused on the dopamine (DA) mechanisms underlying the stress response, as DA release in the PFC appears to be the most reactive of the monoamines to stress exposure (Goldstein et al. 1996). Several lines of evidence indicate that high levels of DA release in the PFC lead to working memory impairment. Stress-induced working memory deficits in rats correlated with increased DA turnover in the rat PFC (Murphy et al. 1996), and could be reversed in rats and monkeys by the DA receptor antagonists haloperidol, SCH23390 and clozapine (Arnsten and GoldmanRakic 1998; Murphy et al. 1997, 1996). D1 receptors appear to be particularly important in this response, as deficits were reversed by the D1 receptor antagonist, SCH23390 (Arnsten and Goldman-Rakic 1998; Murphy et al. 1996), and mimicked by infusion of a selective D1 agonist into the rat PFC (Zahrt et al. 1997). However, the D2 family may also play an important role in the cognitive response to stress. For example, low doses of clozapine were able to prevent stress-induced cognitive deficits, and this compound has high affinity for D4 receptors as well as many other DA and nonDA receptors (Van Tol et al. 1991). D4 receptors are enriched in the primate PFC (Primus et al. 1997) where they are concentrated on interneurons (Mrzljak et al. 1996). D4 receptor message is most dense in layer $\mathrm{V}$ cells in monkey PFC (Lidow et al. 1998), suggesting an important influence on PFC function and its outputs to striatum and thalamus. Interestingly, D4 receptors may be stimulated by norepinephrine as well as DA, as norepinephrine has very high affinity for D4 receptors (12nM; Lanau et al. 1997), and is also released in the PFC during stress exposure (Goldstein et al. 1996).

Might high levels of catecholamines released during stress engage D4 receptors and contribute to PFC cognitive deficits? The recent availability of selective D4 antagonists such as PNU-101387G allows the exploration of this hypothesis for the first time. PNU-101387G has high affinity for $\mathrm{D} 4$ receptors $(\mathrm{Ki}=10 \mathrm{nM})$, but low affinity $(\mathrm{Ki}>2000 \mathrm{nM})$ at other monoamine receptors (Merchant et al. 1996). It has excellent brain penetration and pharmacokinetic properties (Merchant et al. 1996). The current study performed a preliminary examination of the role of $\mathrm{D} 4$ receptors in the stress response by determining whether pretreatment with PNU-101387G would prevent the cognitive deficits induced by the pharmacological stressor, FG7142, in monkeys.

\section{METHODS}

\section{Subjects}

Four female rhesus monkeys (Macaca mulatta) were used in this study, ranging in age from post-adolescent to middle-aged (i.e., estimated ages of 5-14 years). These were the same four animals used in a previous study of clozapine's effects on the stress response (Murphy et al. 1997). Animals were housed individually under standard laboratory conditions. The research was approved by the Yale Animal Care and Use Committee.

\section{Delayed Response Testing}

Cognitive testing occurred in a Wisconsin General Test Apparatus situated in a sound-attenuating room. Background masking noise ( $60 \mathrm{~dB}$, wideband) also was used to minimize auditory distractions. Animals were always tested at the same time of day immediately prior to feeding. Highly palatable food rewards (e.g., chocolate chips) were utilized during testing to minimize the need for dietary regulation. Using these conditions, no problems with motivation were evident.

The monkeys had been previously trained on the two-well delayed response task. During delayed response, the animal watches as the experimenter baits one of two foodwells. The foodwells are then covered with identical cardboard plaques, and an opaque screen is lowered between the animal and the test tray for a specified delay. At the end of this delay, the screen is raised and the animal is allowed to choose. Reward is quasi-randomly distributed between the left and right wells over the 30 trials that make up a daily test session.

To observe the effects of drug on memory capacity, the animals were trained on a variable delayed response task. Delays varied between less than $1 \mathrm{sec}(" 0$ " sec) and the temporal interval that yielded chance performance for each animal. Five different delay lengths were quasi-randomly distributed over the 30 trials that made up a single test session. For example, the range of delays for monkey \#443 were "0," 10, 20, 30 and $40 \mathrm{sec}$. All monkeys performed perfectly at " 0 " sec and had increasing difficulty with progressively longer delays. Delays were adjusted until the animals performed at approximately $83 \%$ correct overall, thus leaving room for either improvement or impairment in performance (chance performance equals 50\% correct). The monkeys were tested twice a week, with 3-4 days separating test sessions. The experimenter testing the monkeys was blind to drug treatment conditions.

\section{General Behavioral Observations}

Changes in arousal and aggression were evaluated during cognitive testing by an experimenter who was familiar with the normative behavior of each animal but 
blind to drug treatment. Sedation and agitation were rated using a nine-point scale, where $0=$ normal level of arousal, I = quieter than usual, II = sedated (drooping eyelids, slowed movements), III = intermittent sleeping, and IV = too sedated to finish testing; $-\mathrm{I}=$ more alert than usual, - II $=$ slight agitation, but not sufficient to disrupt testing, - III = agitation disrupting testing, and $-\mathrm{IV}=$ too agitated to test. Aggression was rated using a seven-point scale, where $0=$ normal level of aggression, $-\mathrm{I}=$ slightly more aggressive, $-\mathrm{II}=$ moderately more aggressive, and $-\mathrm{III}=$ extremely aggressive, $\mathrm{I}=$ slightly more docile, $\mathrm{II}=$ moderately more docile, and III = very docile.

\section{Drug Administration}

PNU-101387G (0.1, 0.2, 0.4, 0.8 and $1.2 \mathrm{mg} / \mathrm{kg}$; Pharmacia Upjohn, Inc., Kalamazoo, MI) was diluted in sterile water and injected i.m. 60 min prior to cognitive testing. Doses were based on estimated plasma levels and D4 affinity of PNU-101387G at the D4 receptors relative to clozapine (Merchant et al. 1996). FG7142 (0.2 mg/kg; Tocris-Cookson, Ballwin, MO) was suspended in a sterile saline vehicle containing $20 \%$ ethanol and injected intramuscularly $30 \mathrm{~min}$ before testing. The number of exposure to FG7142 was minimized as much as possible due to the possibility of seizures with this compound, particularly with repeated use. No seizures were evident in the current study. All monkeys were highly adapted to the injection procedure. Drug treatment could only occur after baseline performance was re-established (i.e., after two consecutive testing times with performance at about $83 \%$ ). Thus, washout periods between drug treatments were a minimum of 10 days.

\section{Data Analysis}

Statistical analyses employed repeated measures designs: the effects of PNU-101387G doses by themselves were analyzed using a one-way analysis of variance with repeated measures (1-ANOVA-R). The effects of (1) water + vehicle vs. water + FG7142, and (2) water + FG7142 vs. PNU-101387G + FG7142 were analyzed with paired $t$-tests (also called dependent $t$-test or $T$-dep), as the $n$ was not sufficient for a two-way analysis of variance. Statistical analyses were performed on a Macintosh LC computer using Systat software.

\section{RESULTS}

\section{PNU-101387G Dose/Response}

A preliminary analysis of the effects of PNU-101387G by itself was performed to ensure that a dosage chosen to challenge the FG7142 response did not improve per- formance on its own. More comprehensive analyses of PNU-101387G's effects on working memory are being performed in other laboratories and thus were not undertaken here. In the present study, all four monkeys received the $0.1,0.2$ and $0.4 \mathrm{mg} / \mathrm{kg}$ doses, three received the $0.8 \mathrm{mg} / \mathrm{kg}$ dose, and one received $1.2 \mathrm{mg} / \mathrm{kg}$ as well. A one-way analysis of variance was performed for the $0,0.1,0.2$ and 0.4 doses given to all animals. This analysis showed no effect of PNU-101387G on delayed response performance $(\mathrm{F}(3,9)=0.44, p=.73)$. Although no effect was shown in group statistics, it is important to note that for each individual animal, a dose could be found that produced performance superior to vehicle control (Figure 1A; $0.2 \mathrm{mg} / \mathrm{kg}$ for two monkeys, 0.4 $\mathrm{mg} / \mathrm{kg}$ for the remaining two animals, see Table 1). Thus, these doses were avoided for these animals when undertaking the FG7142 challenge. The PNU-101387G dose/response curve for monkey \#643 is illustrated in Figure 1B (top graph).

It is also important to note that there were isolated instances when PNU-101387G impaired performance. One monkey (\#9321) was quite impaired by $0.8 \mathrm{mg} / \mathrm{kg}$ PNU-101387G by itself without any evidence of side effects (vehicle: 24/30 trials correct; PNU-101387G: 18/30 trials correct). Interestingly, two monkeys (\#9321 and \#613) refused to test following the initial applications of 0.2 and $0.4 \mathrm{mg} / \mathrm{kg}$ doses, respectively. Both monkeys exhibited marked shivering and loss of interest in the task. These side effects were not evident when the doses were repeated and the monkeys tested normally. Other than these two incidents, PNU-101387G had no effect on behavioral ratings in the four monkeys.

\section{PNU-101387G Challenge of the FG7142 Response}

As had been seen in previous studies, FG7142 with water pretreatment significantly impaired performance compared to water + vehicle alone $(T$-dep $=9.26, \mathrm{df}=$ $3, p=.0027$; Figure 1). Three of the four monkeys exhibited behavioral ratings of - II (moderate agitation) following FG7142 treatment (Wilcoxon, $p=.11$ compared to vehicle). The FG7142 response was challenged with the dose of PNU-101387G higher than that which improved performance on its own. This ensured that the drug dose was sufficient to be biologically active, yet did not have enhancing effects which would interfere with interpretation of the results. The effective dose of PNU-101387G for each animal is shown in Table 1. The two animals improved by $0.2 \mathrm{mg} / \mathrm{kg}$ by itself had their FG7142 response challenged with $0.4 \mathrm{mg} / \mathrm{kg}$; the two animals improved by $0.4 \mathrm{mg} / \mathrm{kg}$ had their FG7142 response challenged with $0.8 \mathrm{mg} / \mathrm{kg}$. One of these animals, \#643, required $1.2 \mathrm{mg} / \mathrm{kg}$ to completely reverse the FG7142 response as the $0.8 \mathrm{mg} / \mathrm{kg}$ dose was only partly effective in restoring performance to baseline levels (Figure 1B, bottom graph). Pretreatment with 
A.

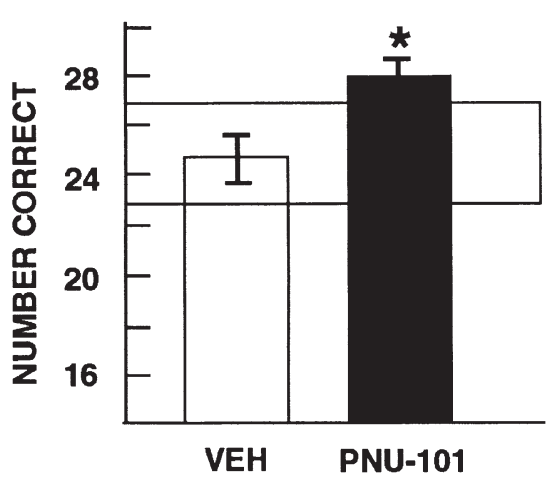

B.
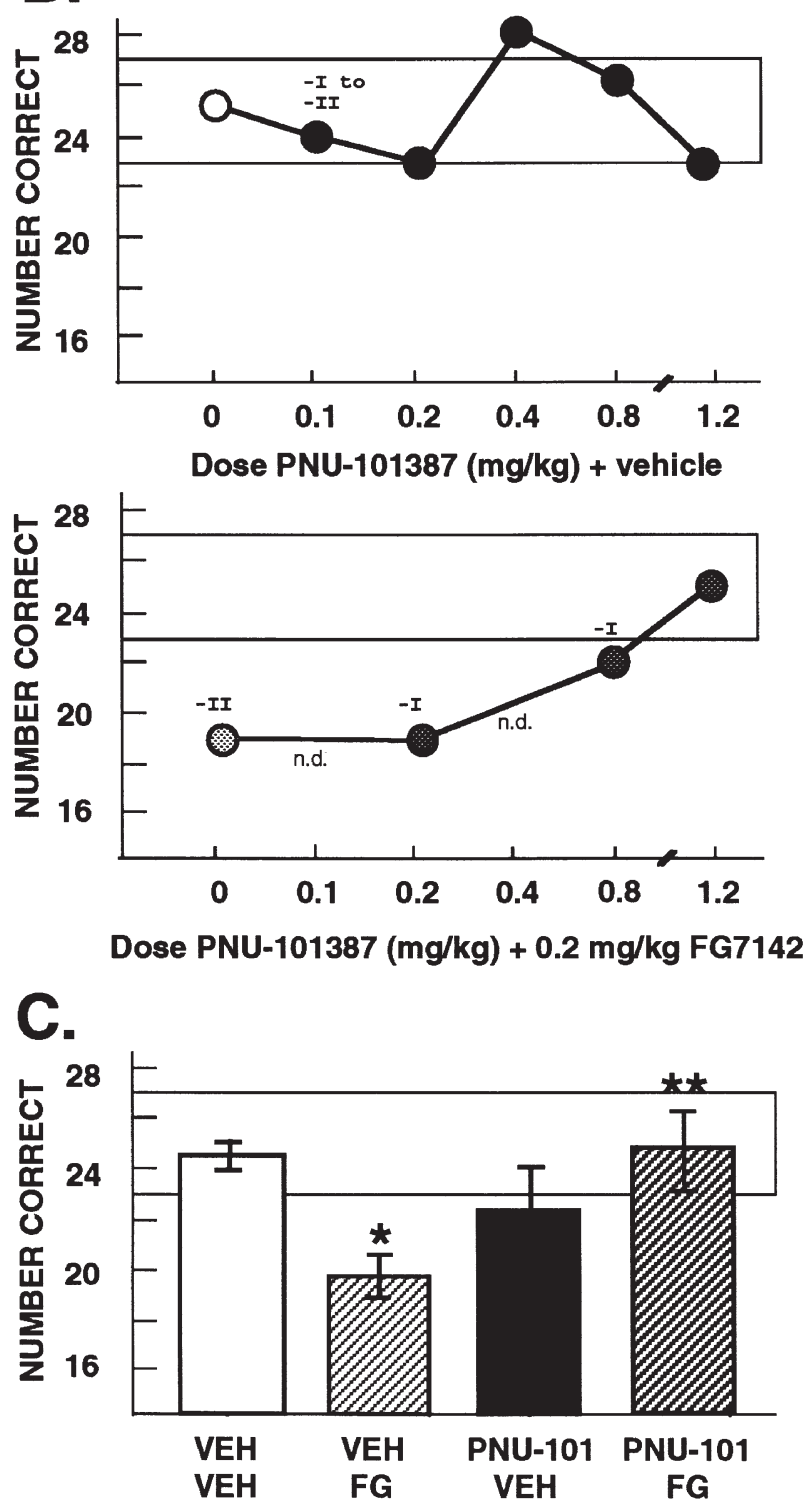

Figure 1. The effects of PNU-101387G on delayed response performance in rhesus monkeys $(n=4)$. The range of performance following saline control treatment (23-27 correct of 30 trials) is outlined by a rectangle in all graphs. (A) A low dose of PNU-101387G was found for each monkey that improved delayed response performance above baseline levels of responding. Results represent mean \pm S.E.M. number correct these doses of PNU-101387G significantly improved performance compared to water pretreatment in FG7142-treated monkeys ( $T$-dep $=5.39, \mathrm{df}=3, p=$ .013; Figure 1C). These doses of PNU-101387G had no significant effect on their own (Figure 1C). PNU101387G also normalized the behavioral agitation ratings in the three monkeys who exhibited agitation with FG7142 treatment (e.g., Figure 1B, bottom graph; median behavioral ratings FG7142 + water: -II; median behavioral ratings FG7142 + PNU-101387G: 0; Wilcoxon $p=.11$ ).

In two animals (\#613 and \#643), the FG7142 response was challenged with PNU-101387G doses lower than those which had improved performance on its own $(0.1$ and $0.2 \mathrm{mg} / \mathrm{kg}$, respectively). These doses had no beneficial effect on the response to FG7142: vehicle + water: 23.9 trials correct; vehicle + PNU-101387G: 23.5 trials correct; FG7142 + water: 19.0 trials correct; FG7142 + PNU-101387G: 17.5 trials correct. Thus, the ability of PNU-101387G to ameliorate the FG7142 response was dose-dependent (e.g., Figure 1B).

\section{DISCUSSION}

The present study replicated earlier findings that FG7142 impairs spatial working memory performance

for the four monkeys. Doses for each monkey are shown in Table 1. *Significantly different from sterile water vehicle control performance. $\mathrm{VEH}=$ sterile water vehicle; PNU-101 = PNU-101387G. (B) The effects of PNU-101387G and FG7142 on the delayed response performance of monkey \#643. Results represent number correct out of a possible 30 trials. Sedation/ agitation are indicated (see text for explanation); no rating shown indicates a score of " 0. ." Top graph: The effects of PNU$101387 \mathrm{G}+$ vehicle. This monkey was slightly improved above baseline performance following the $0.4-\mathrm{mg} / \mathrm{kg}$ dose of PNU101387G. Thus, this dose was not used to challenge the FG7142 response. The mild agitation following the $0.1-\mathrm{mg} / \mathrm{kg}$ dose of PNU-101387G was not observed in other animals. Bottom graph: PNU-101387G produced a dose-related amelioration of the cognitive deficits produced by FG7142 $(0.2 \mathrm{mg} / \mathrm{kg})$. The FG7142 response was partially blocked by $0.8 \mathrm{mg} / \mathrm{kg}$ PNU$101387 \mathrm{G}$, and fully blocked by $1.2 \mathrm{mg} / \mathrm{kg}$. The agitation produced by FG7142 was also ameliorated by PNU-101387G pretreatment. n.d. = not done. (C) The impairment in delayed response performance produced by FG7142 $(0.2 \mathrm{mg} / \mathrm{kg})$ was blocked by PNU-101387G pretreatment in monkeys. Results represent mean \pm S.E.M. number correct out of a possible 30 trials for the four monkeys. Doses of PNU-101387G used to challenge the FG7142 response for each monkey are shown in Table 1 . The range of baseline performance is illustrated. *Significantly different from sterile water vehicle control performance; ${ }^{* *}$ Significantly different from water + FG7142. VEH $=$ sterile water vehicle or sterile saline with $20 \%$ ethanol; PNU$101=$ PNU-101387G; FG = 0.2 mg/kg FG7142. 
Table 1. Doses of PNU-101387G for Individual Rhesus Monkeys

\begin{tabular}{lccc}
\hline Monkey \# & Estimated Age & $\begin{array}{c}\text { Dose that } \\
\text { Improved }\end{array}$ & $\begin{array}{c}\text { Dose that } \\
\text { Blocked } \\
\text { FG7142 }\end{array}$ \\
\hline$\# 443$ & 14 years & $0.2 \mathrm{mg} / \mathrm{kg}$ & $0.4 \mathrm{mg} / \mathrm{kg}$ \\
$\# 613$ & 10 years & $0.2 \mathrm{mg} / \mathrm{kg}$ & $0.4 \mathrm{mg} / \mathrm{kg}$ \\
$\# 643$ & 7 years & $0.4 \mathrm{mg} / \mathrm{kg}$ & $1.2 \mathrm{mg} / \mathrm{kg}$ \\
$\# 9321$ & 5 years & $0.4 \mathrm{mg} / \mathrm{kg}$ & $0.8 \mathrm{mg} / \mathrm{kg}$ \\
\hline
\end{tabular}

in monkeys. Pretreatment with the highly selective D4 receptor antagonist, PNU-101387G, significantly blocked the FG7142 response in monkeys. This pattern of results suggests that D4 receptor mechanisms contribute to the cognitive response to acute stress in primates. These initial results encourage the pursuit of future studies with larger numbers of animals.

The current results suggest there may be a relationship between age of the monkey and response to PNU101387G. This observation is preliminary given the small $n$ of the current study. However, it is noteworthy that the two oldest animals were effected by lower doses of PNU$101387 \mathrm{G}$ than were the two younger monkeys (see Table 1). A similar relationship was observed with clozapine (Murphy et al. 1997). These age/drug relationships may arise from changing levels of DA in the PFC with age. DA levels significantly decrease in the PFC with old age, and there is a large decrease in PFC DA and its metabolites even in monkeys 10-15 years old (Goldman-Rakic and Brown 1981; Wenk et al. 1989). Thus, the two older monkeys may have had less endogenous stimulation of D4 receptors, and thus lower PNU-101387G doses were sufficient to alter performance. Alternatively, PNU-101387G and clozapine may be metabolized more rapidly in younger animals, effectively lowering the administered dose. The relationship between drug response and age needs to be studied in a much larger number of animals with known birth dates. However, the current results support the hypothesis that excessive dopaminergic activity can impair PFC function, and thus that a hyper-dopaminergic state during peri-adolescence (Rosenberg and Lewis 1994) may leave the PFC more vulnerable to disruption (Arnsten 1997; Lewis 1997). These findings may be relevant to stress-sensitive disorders such as schizophrenia which often have their onset during peri-adolescence. Confirmation of these results in a larger number of animals and results of clinical effects of PNU-101387G will help determine the role of D4 dopamine receptors in stress-induced cognitive deficits.

\section{ACKNOWLEDGMENTS}

We thank Lisa Ciavarella and Tracy White for their invaluable technical expertise. This work was supported by PHS grant
MH44866. Dr. Merchant is employed by the company that makes PNU-101387G.

\section{REFERENCES}

Arnsten AFT (1997): Catecholamine regulation of the prefrontal cortex. J Psychopharmacology 11:151-162

Arnsten AFT, Goldman-Rakic PS (1998): Noise stress impairs prefrontal cortical cognitive function in monkeys: Evidence for a hyperdopaminergic mechanism. Arch Gen Psychiatry 55:362-369

Birnbaum S, Gobeske KT, Auerbach J, Taylor JR, Arnsten AFT (1999): A role for norepinephrine in stress-induced cognitive deficits: Alpha-1-adrenoceptor mediation in the prefrontal cortex. Biol Psychiatry 46:1266-1274

Broadbent D (1971): Decision and Stress. London, Academic Press

Goldman PS, Rosvold HE (1970): Localization of function within the dorsolateral prefrontal cortex of the rhesus monkey. Exp Neurol 27:291-304

Goldman-Rakic PS (1987): Circuitry of the primate prefrontal cortex and the regulation of behavior by representational memory. In Plum F (ed), Handbook of Physiology, The Nervous System, Higher Functions of the Brain, vol V. Bethesda, MD, American Physiological Society, pp. 373-417

Goldman-Rakic PS, Brown RM (1981): Regional changes of monoamines in cerebral cortex and subcortical structures of aging rhesus monkeys. Neuroscience 6:177-187

Goldstein LE, Rasmusson AM, Bunney SB, Roth RH (1996): Role of the amygdala in the coordination of behavioral, neuroendocrine and prefrontal cortical monoamine responses to psychological stress in the rat. J Neurosci 16:4787-4798

Hartley LR, Adams RG (1974): Effect of noise on the Stroop test. J Exp Psychol 102:62-66

Kaneyuki H, Yokoo H, Tsuda A, Yoshisa M, Mizuki Y, Yamada M, Tanaka M (1991): Psychological stress increases dopamine turnover selectively in mesoprefrontal dopamine neurons of rats: Reversal by diazepam. Brain Res 557:154-161

Lanau F, Zenner M-T, Civelli O, Hartman DS (1997): Epinephrine and norepinephrine act as potent agonists at the recombinant human dopamine D4 receptor. J Neurochem 68:804-812

Lewis DA (1997): Development of the prefrontal cortex during adolescence: Insights into vulnerable neural circuits in schizophrenia. Neuropsychopharmacology 16:385-398

Lidow MS, Wang F, Cao Y, Goldman-Rakic PS (1998): Layer $\mathrm{V}$ pyramidal neurons bear the majority of mRNAs encoding the five distinct dopamine receptor subtypes in the primate prefrontal cortex. Synapse 28:10-20

Mazure CM (1995): Does stress cause psychiatric illness? In Spiegel D (ed), Progress in Psychiatry, vol. 46. Washington, DC, American Psychiatric Press, p 270

Merchant KM, Gill GS, Harris DW, Huff RM, Eaton MJ, Lookingland K, Lutzke BS, McCall RB, Piercey MF, Schreur PJ, Sethy VH, Smith MW, Svensson KA, Tang AH, Vonvoigtlander PF, Tenbrink RE (1996): Pharmaco- 
logical characterization of U-101387, a dopamine D4 receptor selective antagonist. J Pharmacol Exp Ther 279:1392-1403

Mrzljak L, Bergson C, Pappy M, Levenson R, Huff R, Goldman-Rakic PS (1996): Localization of dopamine D4 receptors in GABAergic neurons of the primate brain. Nature 381:245-248

Murphy B, Roth R, Arnsten AFT (1997): Clozapine reverses the spatial working memory deficits induced by FG7142 in monkeys. Neuropsychopharmacology 16:433-437

Murphy BL, Arnsten AFT, Goldman-Rakic PS, Roth RH (1996): Increased dopamine turnover in the prefrontal cortex impairs spatial working memory performance in rats and monkeys. Proc Nat Acad Sci USA 93:1325-1329

Primus RJ, Thurkauf A, Xu J, Yevich E, McInerney S, Shaw K, Tallman JF, Gallagher DW (1997): II. Localization and characterization of dopamine D4 binding sites in rat and human brain by use of the novel, D4 receptor-selective ligand [3H]NGD 94-1. J Pharmacol Exp Ther 282:1020-1027
Rosenberg DR, Lewis DA (1994): Changes in the dopaminergic innervation of monkey prefrontal cortex during late postnatal development: A tyosine hydroxylase immunohistochemical study. Biol Psychiat 36:272-277

Thierry AM, Tassin JP, Blanc G, Glowinski J (1976): Selective activation of the mesocortical DA system by stress. Nature 263:242-244

Van Tol HHM, Bunzow JR, Guan H-C, Sunahara RK, Seeman P, Niznik HB, Civelli O (1991): Cloning of the gene for a human dopamine D4 receptor with high affinity for the antipsychotic clozapine. Nature 350:610-614

Wenk GL, Pierce DJ, Struble RG, Price DL, Cork LC (1989): Age-related changes in multiple neurotransmitter systems in the monkey brain. Neurobio Aging 10:11-19

Zahrt J, Taylor JR, Mathew RG, Arnsten AFT (1997): Supranormal stimulation of dopamine D1 receptors in the rodent prefrontal cortex impairs spatial working memory performance. J Neurosci 17:8528-8535 